\title{
重畳場を利用した質量分析計
}

\section{Mass Spectrometer with Crossed Electric and Magnetic Fields}

\author{
松田 久* \\ HISASHI MATSUDA \\ (1973年12月25日受理)
}

\begin{abstract}
The merits of a mass spectrometer with crossed electric and magnetic fields are discussed. The electric field is assumed to be a toroidal one (field index $c$ ) and the magnetic field homogeneous. In the case $c=-1$ the stigmatic double focusing is obtained and the Barber's rule holds. If the toroidal electric field is produced by a cylindrical condenser having a pair of Matsuda plates, the directional focusing can be adjusted by changing the electric potential applied to the Matsuda plates and the velocity focusing can be adjusted by changing the ratio of electric and magnetic fields independently to each other. Therefore, all focal adjustments can be done electrically and no mechanical adjustment is necessary. This type of mass spectrometer works also as a single focusing apparatus under very weak magnetic field if appropriate potentials are applied to the condenser electrodes and Matsuda plates.
\end{abstract}

\section{1. まえがき}

現在実用に供せられている筫星分析装置は，単独の 磁場を川いた単収束質量分析計や，単独電場と単独磁 埸を直列に組み合わせた二重収束筑望分析計が大部分 であって，電場と磁場を重ね合わせた重畳場を利川し た装㯰はほとんどない。これは直交した電場と磁場を つくるために狭い磁極の閂に垂直に電㥓を入れること が実際上困難なためであると考えられるが，重畳場に はこれから述べるように非常に良い点もあるので，特 殊な目的にはもっと利用されてもよいのではないかと 思われる。

重畳場を利州した装置として知られているものには， Hipple の発明したサイクロイド型筫是分析部 ${ }^{1)}$ と Wienの速度選択器 (velocity filter) ${ }^{2)}$ とがあり、い ずれも直交した一㥞電場と一㑊磁場よからなる $(\boldsymbol{E} \times \boldsymbol{B})$ 重畳場を利用している。また，一惟磁場と叮䈏電場の 組合せからなる重畳場については Henneberg が詳し く娭討をしている。

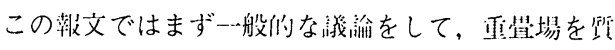
些分析们に利川する埸合にどのような培所があるかを 調べ，それから特殊な目的に川いることができそうな 例をいくつかあげることにする。また，西肾場をつく る坊泣についても寺の可能性を考えてみた。

\section{2. 一 般 論}

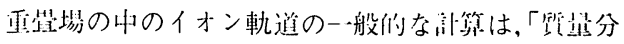

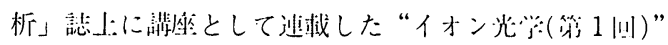
に述へでるので, ここではその紋妆から出発するこ とにする。

门简坐榄 $r=a(1+\rho), \varphi, \quad z=a \zeta$ 朾いると， 中心軌道 $r=a の$ 近くのイオン軌通は，1次还似に揖

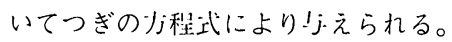

$$
\begin{aligned}
& \frac{\mathrm{d}^{2} \rho}{\mathrm{d} \varphi^{2}}=-x_{r}^{2}(\rho-\delta) \\
& \frac{\mathrm{d}^{2} \rho}{\mathrm{d} \zeta^{2}}=-\varkappa_{2}^{2} \zeta
\end{aligned}
$$

*大阪大学教養部物理学教室 (豊中市待兼山町 1の 1)

Institute of Physics, College of General Education, Osaka University (1-1 Machikaneyama-cho, Toyonaka 560, Japan ) 
ただし

$$
\begin{aligned}
& \varkappa_{r}^{2}=3+l-\frac{a}{a_{m}}(3+l-n)+\left(\frac{a}{a_{m}}\right)^{2} \\
& x_{2}^{2}=-\frac{a}{a_{e}}(1+l)-\frac{a}{a_{m}} n
\end{aligned}
$$

$\delta$ は分散顷で

$$
\delta=\frac{\gamma+\left(2-\frac{a}{u_{m}}\right) \beta}{\varkappa_{\tau}^{2}}
$$

により!jえられる。 $\gamma$ とßはそれぞれ筧拈および速恔

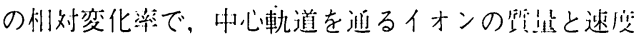
をそれぞれ $m_{0}$ 扩よび $v_{0}$ とするとり，いま䦌题にし ているイオンの钻出 $m$ と速度 $v$ は

$$
\begin{aligned}
& m=m_{0}(1+\gamma) \\
& v=v_{0}(1+\beta)
\end{aligned}
$$

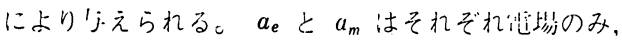

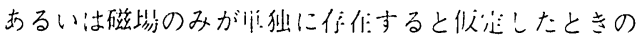

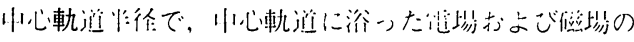

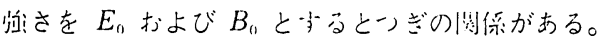

$$
\begin{aligned}
& \frac{m_{0} v_{0}^{2}}{u_{u}}=-e E_{0} \\
& \frac{m_{0} v_{0}}{u_{m}}=-e B_{u} \\
& \frac{1}{u}=\frac{1}{a_{c}}+\frac{1}{a_{m}}
\end{aligned}
$$

さらにしと $n$ とは，それぞれ帒場および磁場を中心軌 道のまわりに Taylor 展開したときの1次の展閉係数 で、軌道斗面内の帒場と磁場は次式により!亦えられる。

$$
\begin{aligned}
& E_{r}=E_{0}(1+\imath \rho+\cdots) \\
& B_{z}=B_{0}(1+n \rho+\cdots)
\end{aligned}
$$

したがって一㥆磁場は $n=0$ により，また円简電場は

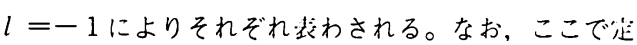
䉝されているnは一般に优われている非一慛磁坋の field index $n$ と符絮が就であることに注意された い。また、トロイダル电場の field index $c=a / R_{e}$ と lとの阅倸は

$$
l=-(1+c)
$$

または

$$
c=-(l+1)
$$

である。 $R_{e}$ は等電位面の $a$ 亿垂直な方向の曲率半径で ある。

重胃場の1次のイオン光学的な性颃は(3)，(4)式およ び(5)式によりすべて蒜わ六れている。すなわち，r方 向の収束性は(3)式で， $z$ 方向の収束性は(4)式で，また 分散の性質は(5)式でそれぞれ与えられる。(5)式からす ぐわかるように,$a / a_{m}=2$ であれば分散法 $\beta$ に無関係 になるので， $a / a_{m}=2$ なる条件を満足するような亚照 場を用いると、二重収束筷㘳分析㖕をつくることがで

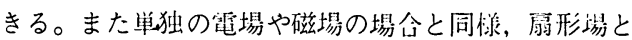
して伙うこともできるし， $\boldsymbol{x}_{r}=\kappa_{z}$ であれば立体收束を 行なわせることもできる。

\section{3. 二重収束質量分析計}

朔節で述べたように

$$
\frac{a}{a_{m}}=2
$$

ならば速度収束の条件が満足される。この場合には华 100 式からわかるように

$$
\frac{a}{a_{e}}=-1
$$

である。このことはつぎのことを空味する。すなわち， 磁場の沙さを半径 $a$ でイオンを曲げる強さの 2 倍に する。同時汇磁場で曲げる力向と反対の力问に笛場を かけ，電場の強さは磁場の強さの半分にする。すると 磁場の強さのちょうど半分が䉓場で打ち消されること になり，その結果，イオンは半径 $a$ で曲げられる。し たがって，速度収束の条件は池場と磁場の強さを調節 することによって，イオン源や像の位題とは無関係に 満足させられる。速度収束の条件を満足させると，才 向の収束性を与える定数 $\boldsymbol{r}_{r}$ と $\varkappa_{2}$ は次式で与えられる。

$$
\begin{aligned}
& \varkappa_{r}^{2}=2+c+2 n \\
& \boldsymbol{x}_{2}^{2}=-c-2 n
\end{aligned}
$$

電場として内简電場，磁場に一椂磁場を用いる場合に は, $c=n=0$ であるので $\varkappa_{r}^{2}=2, \varkappa_{2}^{2}=0$ となる。し たがって，㹝向の收速性は刉简笛場のみの場合と全く 
同様となる。ただし電極にかける電圧は逆向きである。 $r$ 方向と $z$ 方向の同時収束, すなわち立体収束の条 件は

$$
c+2 n=-1
$$

であり、この条件が満たされると， $c$ と $n$ の值の如何 にかかわらず

$$
\boldsymbol{x}_{r}=\boldsymbol{x}_{z}=1
$$

となる。したがって，この場合の $r$ 方向の収束性は一 様磁場のみの場合と全く同様である。扇形場として用 いるときは、Barber の法則がそのまま成立する。

条件(19)からわかるように，同筒電場を用いるときは， 磁場は $n=-1 / 2$ の非一様磁場となり, 一様磁場と組 み合わせるべき電場は $c=-1$ のトロイダル電場であ る。 $c=-1$ の電場は, 軌道平面に垂直な力向の曲り 方が球面と反対になっているような，つまり馬の鞍の ような形の樰によってつくることができるが, 円筒 コンデンサーの電極の上下に補助電極 (Matsuda plate）をつけて，それに適当な電压を与えることに よっても实現することができる。

Fig. 1 はこのような電極構造の一例で, Matsuda plateに約 $0.25 \phi_{0}$ の電圧を加えたときに $c=-1$ となる。 重瞕場の場介，電極を磁場の中に入れなければならな いので，電極全体の高さをあまり高くできない点を考
えると、このように電極間隙と電極の高さとの比が 1 : 2であるような構造は都合がよい。さらにこのよう な電場を用いると, Matsuda plat $\mathrm{e} の$ 電圧を変えるこ とによって $c$ の值を自由に変化させることができる ので, それによっで を変化させ, 焦点距離を自由に 電気的に調節することができる。

以上述べたように、この型の二重収束質量分析計で は，速度収束は電場と磁場の強さを変えることによっ て調節し，方向収束はMatsuda plate の電圧を変え ることによって調整できるので，両者の間に関連はな く, 互に独立に全く電気的な手段のみによって焦点調 節を行なうことができて非常に便利である。

彽来の電場と磁場を直列に配置した二重収束質量分 析計では，電磁石を互に垂直な 2 方向に動かして焦点 調節をするが，方向収束と速度収束が互に関連してい るため逐次法により二重収束点を求めなければならず， かなり面倒であったのに比べて，この装置では機械的 な調節部分は全く不用で, 簡単に二重収束の条件が見 出せることになる。

一様磁場と $c=-1$ の電場を組み合わせた装置では, $r$ 方向の収束性が一様磁場のみを用いた場合と全く一 致するので，電極を全部アースすると他の部分をその ままにして単収束質量分析計として働かせることもで きる，したがって，目的に応じて同じ装置を単収束装 置としても，あるいは二重収束装置としても使うこと ができる。二重収束装置として働かせるときには，磁

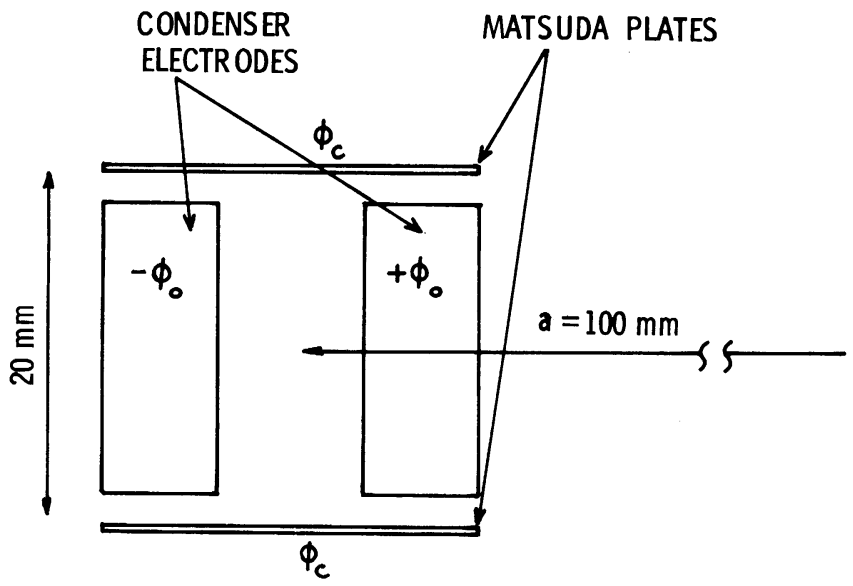

Fig. 1. Cross section of condenser electrodes having Matsuda plates. 
場は 2 倍の強さが必要であるが，啠量分散も 2 倍とな る。

この種の装置を実際につくるとすると、90型また は $60^{\circ}$ 型が適当であろう。

\section{4. 磁場を弱くする方法}

あまり大きい分解能は必要でないが，できるだけ簡 単に質还分析をしたいという場合がよくある。たとえ ば, vacuum anal yzer などがこれである。このよう な場合すぐに考えられることは軌道半径を小さくする ことであり，事実半径の小さい小型マス・スペクトロ メーターがよく使われている。しかし，磁場の強さ $B$ と軌道半径 $a_{m}$ の問にはよく知られた。

$$
B a_{m}=146 \sqrt{M V}
$$

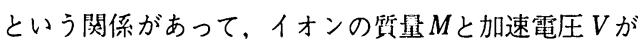
同じであるとすると， $a_{m}$ をさくすれば当然 $B$ を大き くしなければならない。強い磁場をつくるには電磁石 も大きくなり，簡単なマス・スペクトロメーターとい う概念から遠ざかることになってしまう。そこで弱い 磁場でも働くマス・スペクトロメーターが必要になっ てくる。

装置を二重収束にして加速電圧を下げるというのも 一つの解決の方向であるが，あまり加速電圧を下げる とイオン源の能率が悪くなる心配がある。加速電圧を 下げないで磁場を弱くする方法の一つの可能性が重畳 場を用いた装置によって考えられる。

いま，イオン源で一定エネルギーで加速されたイオ ンが得られるものとして， $\gamma+2 \beta=0$ とする。する と(5)式は

$$
\delta=\frac{1}{\varkappa_{r}^{2}} \cdot \frac{a}{2 a_{m}} \gamma
$$

となる。 $a / a_{m}$ を小さくすると軌道半径 $a$ は同じでも磁 場を弱くすることができる。そのときの質是分散は(22) 式で与えられる。これからわかるように， $x_{r}$ が同じで あれば，磁場を弱くすると共に分解能も低下する。

$a / a_{m}$ をある値にきめたときの $\boldsymbol{x}_{r}$ と $\boldsymbol{x}_{\boldsymbol{z}}$ は(3)，(4)式で求 められ， $c$ と $n$ に関係しており， $\boldsymbol{x}_{r}$ が小さくなるよう にすると質量分散を大きくすることができる。

一様磁場（ $n=0 ）$ を用いた場合， $a / a_{m}$ のいろいろ な値に対して，常に $\boldsymbol{x}_{r}=1$ とするような $c$ の值および そのときの $\boldsymbol{x}_{z}$ の值をTable 1 にあげておく。 また Table 1 の下段には，立体収束の条件 $\boldsymbol{x}_{r}=\boldsymbol{x}_{z}$ を満たす べき $c$ の值とそのときの $\boldsymbol{x}_{r}, \boldsymbol{x}_{z}$ の值も示してある。

以上述べたように，重畳場を用いた装置では $c$ の值 を調節することによって，a/a の強さを自由に変えることができる。勿論そのときに は電場の強さも調節する必要があるが、これは容易に 行なえることである。このような目的にも，Matsuda plate を用いた Fig. 1 の構造の電場は非常に都合がよ い。とくに $\boldsymbol{x}_{r}=1$ の場合にはBarber の法則を満足す るので, 電場をつくる電圧とその極性およびMatsuda plate の電圧を調節することにより，装収束装置から 二重収束装置まで（第 3 章参照），また上述の弱い磁 場で高質埋域をカバーすることなど，すべての機能を 同一の装置で行なわせることができる点は注目に值す る。

\section{5. - 例}

最後に一例として, 軌道半径 $10 \mathrm{~cm}$ の装置を考えてみ よう。Table 2 に単収束, 二重収束，あるいは弱磁場 装置として働かせた場合の $a / a_{m}, c$ の值と, 磁場の 強さおよび分解能があげてある。磁場の強さは加速電 圧 $1000 \mathrm{~V}$, 質量数 100 の 1 価イオンに対する值である。 分解能は $0.1 \mathrm{~mm}$ のスリットを用いたときの半值幅であ

Table 1. Values of $c, \boldsymbol{x}_{r}, \boldsymbol{x}_{z}$ corresponding to different $a / a_{m}$ values. Magnetic field is homogeneous.

\begin{tabular}{cllllll}
\hline$a / a_{m}$ & 0.1 & 0.2 & 0.3 & 0.4 & 0.5 & 1 \\
\hline$c$ & 0.9 & 0.8 & 0.7 & 0.6 & 0.5 & - \\
$\boldsymbol{x}_{r}$ & 1 & 1 & 1 & 1 & 1 & 1 \\
$\boldsymbol{x}_{\boldsymbol{z}}$ & 0.9 & 0.8 & 0.7 & 0,6 & 0.5 & 0 \\
\hline$c$ & 1.006 & 1.025 & 1.064 & 1,133 & 1.25 & \\
$\boldsymbol{x}_{r}=\boldsymbol{x}_{z}$ & 0.951 & 0.906 & 0.863 & 0,825 & 0.791 & \\
\hline
\end{tabular}




\section{重畳場を利用した質量分析計}

Table 2. An example of a mass spectrometer with crossed fields. $a=10 \mathrm{~cm}, \varkappa_{r}=1$.

\begin{tabular}{|c|c|c|c|c|c|}
\hline & $a / a_{m}$ & $c$ & $\begin{array}{l}B \text { (gauss) } \\
\text { at } \quad A=100 \\
\quad V=1000 \mathrm{~V}\end{array}$ & $\begin{array}{l}R \\
\text { for } \\
s=0.1 \mathrm{~mm}\end{array}$ & $x_{z}$ \\
\hline Single focus & 1 & - & 4500 & 1000 & 0 \\
\hline Double focus & 2 & -1 & 9000 & 2000 & 1 \\
\hline Weak $B$ & 0.5 & 0.5 & 2250 & 500 & 0.5 \\
\hline " & 0.2 & 0.8 & 900 & 200 & 0.8 \\
\hline " & 0.1 & 0.9 & 450 & 100 & 0.9 \\
\hline
\end{tabular}

る。どの場合でも $x_{r}=1$ で，イオン源とコレクターの 位置関係は同じである。すなわち， $\phi=90^{\circ}$ ならば $l^{\prime}$ $=l^{\prime \prime}=10 \mathrm{~cm}$ であり, $\phi=60^{\circ}$ ならば $l^{\prime}=l^{\prime \prime}=17.3 \mathrm{~cm}$ で ある。 $z$ 方向の収束性をきめる $x_{z}$ の值も Table 2 に あげておく。

Table 2 の最後に示した $a / a_{m}=0.1$ という場合では, 磁場の強さは $A=100$ で450ガウスでよい。このような 場合には，鉄を使わない空心のコイルで磁場をつくる ことも可能となるであろう。空心コイルを用いるとイ ンダクタンスが小さいので, 高速走査は楽になる。質
量数の大きいところは，パルス的に磁場走査をしてマ ス・スペクトルをとれば，発熱を避けることができる。

\section{文献}

1) W. Bleakney and J.A. Hipple, Phys. Rev., 53, 521 (1938).

2) W. Wien, Ann. Phys., 65, 440(1898): $8,260(1902)$.

3) W. Henneberg, Ann. Phys., 19, 335(1934).

4 ）松田 久, 質量分析, 12, 47(1964).

5) H. Matsuda, Rev. Sci. Instr., 32, 850(1961)：質量分析, 17, 8(1961). 